\title{
CONVERSÃO DE GLICEROL EM ÁCIDO LÁTICO UTILIZANDO CATALISADOR DE PALÁDIO SUPORTADO EM CARBONO ATIVADO
}

\author{
F. L. MARQUES ${ }^{1}$, F. J. S. BARROS ${ }^{1}$ e R. S. VIEIRA ${ }^{1}$ \\ ${ }^{1}$ Universidade Federal do Ceará, Departamento de Engenharia Química \\ E-mail para contato: fabio.marques@gpsa.ufc.br
}

\begin{abstract}
RESUMO - O glicerol é o principal subproduto da indústria de biodiesel e é também uma matéria-prima muito versátil, podendo ser utilizado na produção de produtos químicos, polímeros e combustíveis. Recentemente vários autores têm relatado a conversão de glicerol em ácido lático, um importante composto com ampla aplicação na indústria química, farmacêutica e alimentícia. Neste trabalho foi possível sintetizar e caracterizar um catalisador de paládio suportado em carbono ativado $(\mathrm{Pd} / \mathrm{C})$ e verificar seu desempenho na reação de conversão de glicerol em ácido lático. Através de uma técnica de deposição foi possível obter um catalisador com teor médio de 2,52\% em massa do metal. Este catalisador foi testado em reator de batelada, partindose de uma solução 0,5 M de glicerol e 0,55 M de $\mathrm{NaOH}$ (razão molar $\mathrm{NaOH}$ :glicerol de 1,1 ) e carga de catalisador de $0,5 \% \mathrm{p} / \mathrm{v}$, nas temperaturas de $200^{\circ} \mathrm{C}$ e $230^{\circ} \mathrm{C}$. A conversão de glicerol, a seletividade a ácido lático e o rendimento de ácido lático foram monitorados durante 240 minutos de reação. O melhor desempenho ocorreu na temperatura de $230^{\circ} \mathrm{C}$ e 180 minutos de reação. Nestas condições foi possível obter 95,9\% de conversão de glicerol e 52,3\% de seletividade a ácido lático, resultando em um rendimento em ácido lático de 50,1\%. Além disso, o catalisador apresentou estabilidade diante das condições de reação empregadas, sendo reutilizado por cinco ciclos de reação sem perda significativa de atividade ou seletividade.
\end{abstract}

\section{INTRODUÇÃO}

A redução das reservas mundiais e o consequente aumento do preço do petróleo, aliados à maior conscientização das pessoas quanto às questões ambientais, tem resultado em uma crescente produção de biodiesel nos últimos anos. Este aumento da produção de biodiesel tem como consequência uma elevação na produção do glicerol, seu principal subproduto, em quantidades acima da sua demanda atual, causando preocupação quanto à disposição final deste material. Por outro lado, o glicerol é uma molécula versátil e que tem mostrado grande potencial de utilização em novas aplicações, como a incorporação na alimentação de animais e como matéria-prima para a obtenção de compostos químicos de maior valor agregado. Neste último caso, a utilização do glicerol apresenta diversas vantagens, como a grande disponibilidade de material proveniente da produção de biodiesel e o fato do glicerol ser um composto não tóxico, alimentício, biossustentável e biodegradável (Zhou et al., 2008).

A partir de 2005 surgem na literatura científica alguns artigos relatando a conversão do glicerol em ácido lático, um composto químico com ampla aplicação industrial e que vem 
despertando interesse por ser o monômero utilizado na produção do poliácido lático, um plástico biodegradável capaz de substituir as resinas de origem fóssil em muitas aplicações. Nestes artigos descreve-se a síntese hidrotérmica alcalina, um processo em que são utilizadas soluções aquosas fortemente alcalinas e altas temperaturas para se obter até $90 \%$ de rendimento de reação (Kishida et al., 2005; Shen et al., 2009). Apesar disto, as condições rigorosas necessárias para a realização do processo impõem restrições quanto ao material utilizado na construção dos equipamentos e o custo energético do mesmo. Neste sentido, o desenvolvimento de catalisadores heterogêneos que permitam a realização da reação a temperaturas mais brandas seria altamente desejável.

A literatura existente sugere que o mecanismo pelo qual o glicerol é convertido em ácido lático passa pela desidrogenação do glicerol a gliceraldeído, sendo esta uma etapa chave nesta reação. Este trabalho buscou verificar se um catalisador heterogêneo contendo como fase ativa o paládio, um metal com extensa aplicação como catalisador em reações de hidrogenação e desidrogenação de moléculas orgânicas (Semikolenov, 1992), poderia ser utilizado vantajosamente nesta reação. O material escolhido para ser o suporte desta fase ativa foi o carbono ativado, por possuir uma estrutura resistente às condições alcalinas nas quais a reação acontece, além de elevada área superficial e baixo custo.

\section{MATERIAIS E MÉTODOS}

\subsection{Preparação do catalisador $P d / C$}

O procedimento de preparação do catalisador foi adaptado daquele descrito por Kubota et al. (2012). Carbono ativado comercial foi pré-tratado com uma solução de $\mathrm{HNO}_{3} 10 \% \mathrm{p} / \mathrm{v}$ $(5 \mathrm{~mL} / \mathrm{g})$ por 3 horas a $80^{\circ} \mathrm{C}$ sobre uma chapa aquecedora dotada de agitação magnética. Este procedimento foi adotado porque, segundo Toebes et al. (2001), a baixa reatividade da superfície do carbono torna difícil a deposição de metais. Neste caso, o pré-tratamento do carbono em um ambiente oxidante é usado para introduzir grupos superficiais contendo oxigênio e, desta foma, melhorar as interações com o metal. Segundo Shamsijazeyi e Kaghazchi (2010) o tratamento do carbono com agentes oxidantes como o ácido nítrico pode mudar a variedade de grupos funcionais oxigenados superficiais pela introdução de novos grupos ácidos no carbono ativado. Carboxila, quinona e lactona são exemplos de grupos ácidos que, devido à sua carga negativa, melhoram a interação entre a superfície do carbono e o precursor metálico positivamente carregado. Paládio foi impregnado no carbono ativado pré-tratado utilizando como precursor o $\mathrm{PdCl}_{2}$. A carga teórica de metal sobre o suporte foi de $5 \%$. Uma solução de $\mathrm{PdCl}_{2}(87,7 \mathrm{mg}, 0,496 \mathrm{mmol})$ foi preparada pela suspensão do precursor em água (10 mL), seguida pela adição de $12 \mathrm{~mL}$ de uma solução de $\mathrm{HCl} 1 \mathrm{M}$. A esta solução foi adicionado $1,0 \mathrm{~g}$ de carbono ativado e agitado por 20 horas a $30^{\circ} \mathrm{C}$ sobre uma chapa aquecedora dotada de agitação magnética. $\mathrm{O}$ sólido obtido foi separado por filtração a vácuo e disperso em uma solução de $\mathrm{Na}_{2} \mathrm{CO}_{3}(419,6 \mathrm{mg}, 4,0 \mathrm{mmol})$ em água (15 mL) na mesma temperatura. Depois de 3 horas, formaldeído $(37 \%, 330 \mu \mathrm{L}, 4,4 \mathrm{mmol})$ foi adicionado e a suspensão mantida sob agitação por 2 horas a $60^{\circ} \mathrm{C}$ sobre uma chapa aquecedora dotada de agitação magnética. O catalisador foi recuperado por filtração a vácuo, sendo lavado abundantemente com água deionisada $(250 \mathrm{~mL})$ neste processo. A forma final do catalisador foi obtida após a secagem do mesmo ao ar por 16 horas. 


\subsection{Testes catalíticos}

Os testes foram realizados em reator do tipo batelada com agitação, marca Parr, feito em aço inoxidável, com volume útil de $300 \mathrm{~mL}$ e capaz de trabalhar com pressões de até 20,7 $\mathrm{MPa}$ e temperaturas de até $350^{\circ} \mathrm{C}$. Em cada teste era alimentado no reator $200 \mathrm{~mL}$ de uma solução 0,5 M de glicerol e 0,55 $\mathrm{M}$ de hidróxido de sódio $(\mathrm{NaOH})$ (razão molar $\mathrm{NaOH}$ : glicerol de 1,1:1) e 1,0 g de catalisador. O reator era fechado e depois de atingida a temperatura desejada iniciava-se a contagem do tempo de reação programado. Decorrido este tempo, o reator era resfriado e o material presente coletado para análises químicas. $\mathrm{O}$ acompanhamento do desempenho da reação com o tempo era realizado pela coleta de amostras através de um tubo inserido no meio da massa reacional e de uma válvula de agulha, sendo condensadas pela passagem através de uma serpentina imersa em água gelada. $\mathrm{O}$ catalisador usado e o produto da reação eram separados por decantação ou filtração a vácuo através de membranas de 0,45 $\mu \mathrm{m}$ de abertura de poros. Nos testes de estabilidade, após cada ciclo o catalisador era recuperado do produto por filtração a vácuo, lavado abundantemente com água deionizada e seco a temperatura ambiente antes de ser utilizado em um novo ciclo de reação.

\subsection{Métodos analíticos}

Determinação do teor de glicerol e ácido lático por Cromatografia Líquida de Alta Eficiência (CLAE): As amostras obtidas durante os testes catalíticos eram analisadas quanto ao teor de glicerol e ácido lático através de cromatografia líquida de alta eficiência (CLAE) utilizando uma metodologia adaptada de Long et al. (2011). As amostras eram diluidas em $\mathrm{H}_{2} \mathrm{SO}_{4}$ 0,5 M para que seu $\mathrm{pH}$ ficasse abaixo de 3,0 (requisito da coluna cromatográfica utilizada). O equipamento utilizado era um sistema UFLC Prominence da Shimadzu, composto pela bomba LC-20AD, o degaseificador DGU-20A5, o forno CTO-20A e o detector de índice de refração RID-10A. O sistema era equipado com uma coluna Biorad Aminex HPX-87H e operava a $60^{\circ} \mathrm{C}$ com uma solução $5 \mathrm{mM}$ de $\mathrm{H}_{2} \mathrm{SO}_{4}$ como eluente. A vazão era de $0,6 \mathrm{~mL} / \mathrm{min}$ e o volume de injeção era $20 \mu \mathrm{L}$. Foram obtidas curvas com faixa linear nas concentrações de 0,0 a $18,0 \mathrm{~g} / \mathrm{L}$ de cada um dos compostos e coeficiente de determinação $\left(\mathrm{R}^{2}\right)$ maior que 0,98 para ambos.

Cálculo da conversão de glicerol, da seletividade a ácido lático e do rendimento em ácido lático: Os valores de conversão de glicerol, seletividade a ácido lático e rendimento em ácido lático mostrados neste trabalho foram calculados pelas seguintes equações:

$$
\begin{aligned}
\text { Conversâo de glicerol }(\mathrm{em} \% \text { molar }) & =\frac{\lfloor\text { Glicerol inicial }]-\lfloor\text { Glicerol final }]}{[\text { Glicerol inicial }]} \times 100 \\
\text { Seletividade a Ácido Lático }(\mathrm{em} \% \text { molar }) & =\frac{\lfloor\text { Ácido lảtico }\rfloor}{[\text { Glicerol inicial }]-[\text { Glicerol final }]} \times 100 \\
\text { Rendimento em Ấcido Lático }(\mathrm{em} \% \text { molar }) & =\text { Conv }(\%) \times \text { Sel }(\%) \div 100
\end{aligned}
$$

Nas equações acima os colchetes significam "concentração molar".

Espectroscopia por dispersão de energia de raios X (EDS): Esta técnica foi utilizada para quantificar o percentual de paládio depositado sobre o carbono ativado. A análise foi realizada 
em um microscópio eletrônico de varredura modelo Helios Nanolab 650 da FEI com um detector de EDS da Oxford. A tensão de aceleração aplicada foi de $10 \mathrm{kV}$ e a corrente do feixe de $1,6 \mathrm{nA}$.

\section{RESULTADOS E DISCUSSÃO}

\subsection{Espectroscopia por dispersão de energia de raios X (EDS)}

A espectroscopia por dispersão de energia de raios $\mathrm{X}$ foi utilizada para a quantificação do teor de paládio no catalisador sintetizado. Foram analisados cinco pontos sobre a superfície do catalisador preparado para microscopia eletrônica de varredura e obtidos os valores de $2,72 \%, 3,15 \%, 2,23 \%, 2,30$ e 2,19\% em porcentagem mássica, para os pontos 1, 2, 3, 4 e 5, respectivamente. $\mathrm{O}$ valor médio entre estas medidas é $2,52 \%$ e revela uma distribuição uniforme do metal sobre a superfície do suporte. Por outro lado, considerando que o catalisador foi preparado para ter uma carga de $5 \%$ em massa de paládio, verifica-se que o procedimento de impregnação do metal no suporte foi somente parcialmente efetivo. Este resultado pode ser explicado pela conhecida inerticidade química do carbono ativado e a consequente resistência do mesmo em formar ligações químicas com metais, apesar do tratamento com ácido nítrico realizado previamente à utilização deste material como suporte para o catalisador.

\subsection{Evolução da conversão de glicerol em função do tempo de reação}

A Figura 1 mostra como a conversão de glicerol variou em relação ao tempo de reação para as temperaturas de 200 e $230^{\circ} \mathrm{C}$. Pode-se notar um aumento contínuo da conversão com o aumento do tempo de reação para as duas temperaturas. No entanto, para $200^{\circ} \mathrm{C}$ a conversão máxima obtida foi de $71,8 \%$ enquanto que para a temperatura de $230^{\circ} \mathrm{C}$ esta foi de $99,1 \%$, ao final de 4 horas de reação. Conforme relatado por Kishida et al. (2005), a temperatura tem grande efeito na conversão de glicerol em ácido lático. Este efeito também pode ser evidenciado neste trabalho, pela diferença existente entre as duas curvas mostradas na Figura 1. Além disso, enquanto no processo hidrotérmico não houve conversão a $260^{\circ} \mathrm{C}$ e 60 minutos de reação (Kishida et al., 2005), com o catalisador Pd/C é possível observar cerca de $75 \%$ de conversão a $230^{\circ} \mathrm{C}$ e mesmo tempo de reação. Adicionalmente, experimentos realizados a $230^{\circ} \mathrm{C}$ e 180 minutos de tempo de reação utilizando apenas o suporte do catalisador forneceram rendimentos de cerca de $5 \%$, comprovando que o paládio impregnado no suporte é o verdadeiro catalisador da reação. 


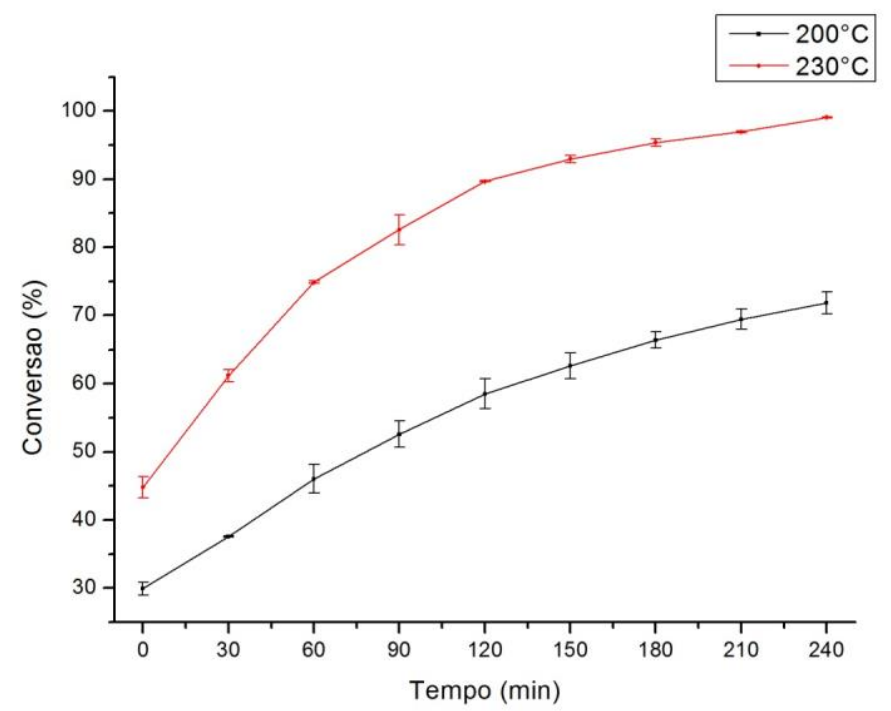

Figura 1 - Evolução da conversão de glicerol em função do tempo de reação.

Valores expressos como média \pm desvio padrão, $\mathrm{n}=2$.

\subsection{Evolução da seletividade a ácido lático em função do tempo de reação}

A Figura 2 mostra como a seletividade a ácido lático variou em relação ao tempo de reação para as temperaturas de 200 e $230^{\circ} \mathrm{C}$. Na temperatura de $200^{\circ} \mathrm{C}$ a seletividade aumenta progressivamente até 90 minutos de reação, quando se estabiliza em um valor próximo de $46,0 \%$. Para a temperatura de $230^{\circ} \mathrm{C}$ verifica-se que a seletividade oscila em torno deste mesmo valor durante todo experimento. Estes dados mostram que o aumento da temperatura favorece o atingimento do máximo de seletividade a ácido lático em menos tempo de reação.

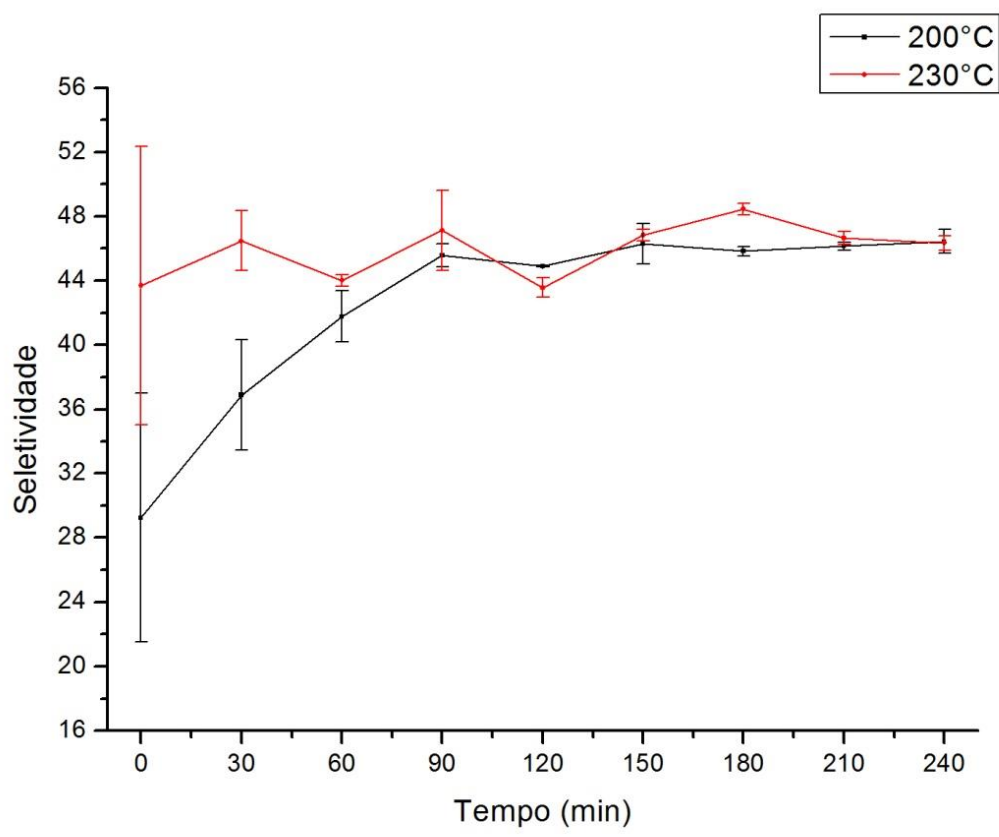

Figura 2 - Evolução da seletividade a ácido lático em função do tempo de reação.

Valores expressos como média \pm desvio padrão, $\mathrm{n}=2$. 
É sabido que as três hidroxilas do glicerol são altamente reativas em meio ácido ou básico, de modo que nas condições utilizadas neste trabalho outras reações ocorrem simultaneamente, gerando diversos produtos indesejados e reduzindo a seletividade a ácido lático. Dentre estes produtos citados na literatura encontram-se produtos líquidos, como o 1,2propanodiol e o ácido glicérico, e produtos gasosos, como o metano e o gás carbônico. A presença deste último composto, na forma de carbonatos solúveis, era evidenciada nas amostras coletadas neste estudo quando as mesmas eram acidificadas para serem submetidas à análise por CLAE.

\subsection{Evolução do rendimento em ácido lático em função do tempo de reação}

A Figura 3 mostra a evolução do rendimento em ácido lático com o tempo de reação para as temperaturas de 200 e $230^{\circ} \mathrm{C}$. Para a temperatura de $200^{\circ} \mathrm{C}$ verifica-se um aumento contínuo do rendimento por todo o tempo de duração do teste, que foi estabelecido em 4 horas, mas com tendência à estabilidade na última hora de reação. $\mathrm{O}$ rendimento médio final nesta temperatura foi de $33,4 \%$. Para a temperatura de $230^{\circ} \mathrm{C}$ verifica-se níveis mais elevados de rendimento desde o início da reação e o alcance da estabilidade após 180 minutos de reação em valores próximos a 46,0\%. Principalmente para esta temperatura verifica-se que o rendimento em ácido lático aumenta drasticamente com o aumento no tempo de reação no estágio inicial, e então o aumento é mais lento, o que mostra claramente o comportamento cinético de uma reação de primeira ordem (Shen et al., 2009).

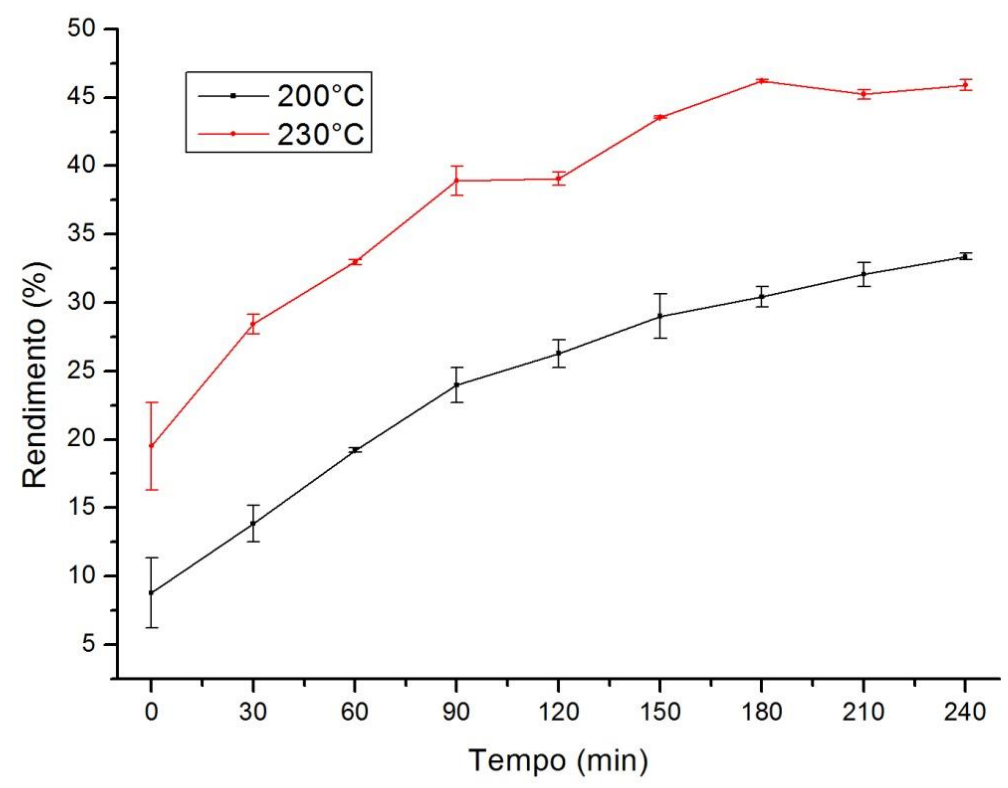

Figura 3 - Evolução do rendimento em ácido lático em função do tempo de reação. Valores expressos como média \pm desvio padrão, $\mathrm{n}=2$. 


\subsection{Estabilidade do catalisador}

Os dados de rendimento em ácido lático em função do tempo de reação mostram que os melhores resultados foram obtidos na temperatura de $230^{\circ} \mathrm{C}$ e que a partir de 180 minutos este parâmetro já se encontra estabilizado, não havendo necessidade de prolongar a reação por mais uma hora. Desta forma, estes valores de temperatura e tempo de reação foram definidos como a melhor condição de operação para o sistema reacional proposto e esta condição foi escolhida para se testar a estabilidade do catalisador, utilizando a mesma porção do catalisador por 5 ciclos de reação seguidos. A Figura 4 mostra que o catalisador sintetizado é estável nas condições de reação testadas, mantendo os mesmos níveis de conversão, seletividade e rendimento obtidos após o primeiro uso. A conversão, seletividade e rendimento médios entre os cinco ciclos foram $95,9 \%, 52,3 \%$ e 50,1\%, respectivamente.

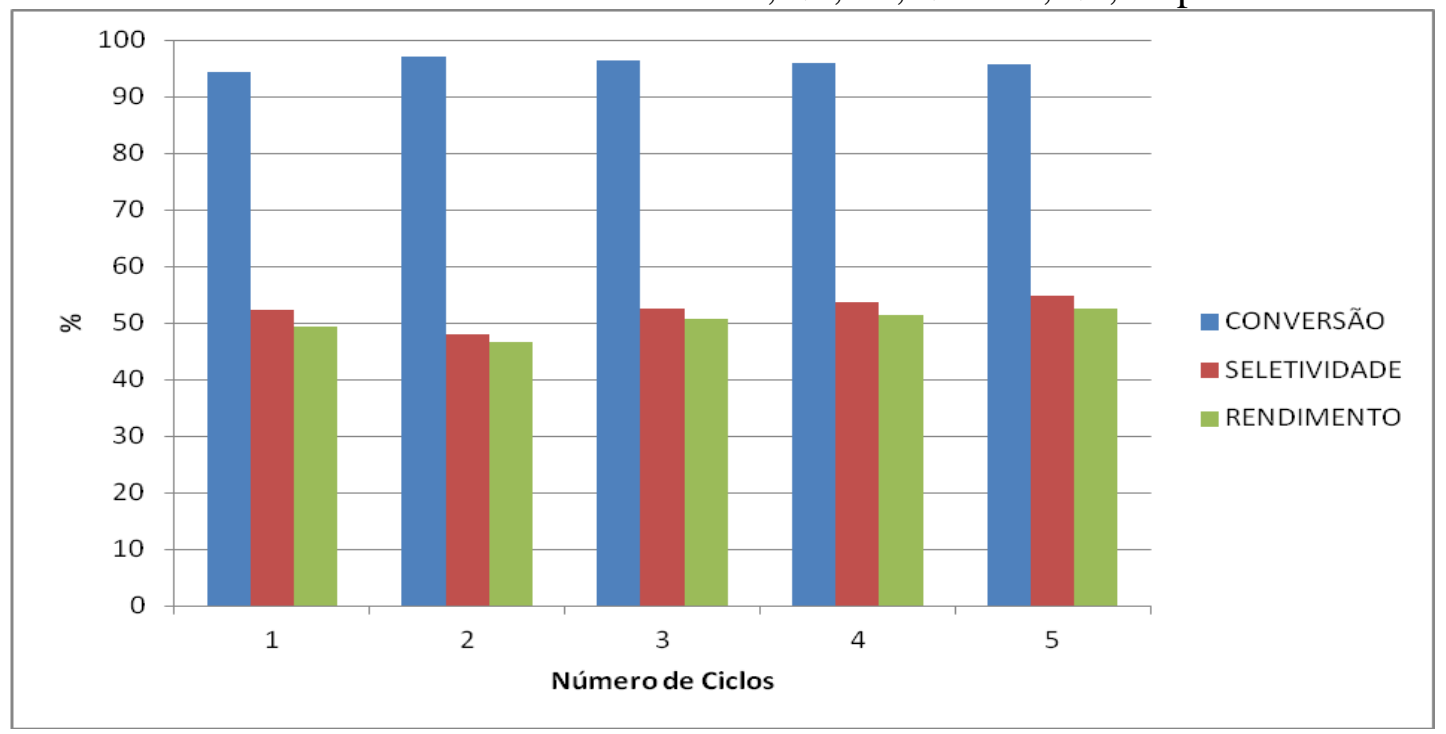

Figura 4 - Desempenho do catalisador $\mathrm{Pd} / \mathrm{C}$ em sucessivos ciclos de reação.

Condições de teste: $100 \mathrm{~mL}$ de solução 0,5 $\mathrm{M}$ de glicerol e 0,55 $\mathrm{M}$ de $\mathrm{NaOH}, 0,5 \mathrm{~g}$ de catalisador, $230^{\circ} \mathrm{C}$ e 180 minutos de reação.

\section{CONCLUSÕES}

Os resultados obtidos permitem concluir que a metodologia de síntese do catalisador utilizada mostrou-se efetiva em produzir um catalisador ativo, seletivo e estável para a conversão de glicerol em ácido lático, contendo um teor médio de $2,52 \%$ de paládio. $\mathrm{O}$ catalisador foi bastante ativo na reação estudada, atingindo conversões maiores que $95 \% \mathrm{em}$ 180 minutos de reação a $230^{\circ} \mathrm{C}$. Esta temperatura é $70^{\circ} \mathrm{C}$ menor que a utilizada no processo hidrotérmico, sem catalisador. Além disso, apresentou seletividade a ácido lático maior que $50 \%$. Por fim, sua estabilidade diante das condições de reação estudadas foi inquestionável, resistindo a cinco ciclos de reuso sem demonstrar nenhum sinal de perda de desempenho. Dentro da região experimental coberta por este estudo as melhores condições de reação foram: concentração de glicerol $0,5 \mathrm{M}$, razão molar $\mathrm{NaOH}$ :glicerol de 1,1 , carga de catalisador de $0,5 \%$, temperatura de $230^{\circ} \mathrm{C}$ e tempo de reação de 180 minutos. Nestas condições foi possível obter conversão, seletividade e rendimento médios de 95,9\%, 52,3\% e $50,1 \%$, respectivamente. 


\section{REFERÊNCIAS}

KISHIDA, H.; JIN, F.; ZHOU, Z.; MORYIA, T.; ENOMOTO, H. Conversion of glycerin into lactic acid by alkaline hydrothermal reaction. Chem. Lett., v. 34, p. 1560-1561, 2005

KUBOTA, T.; OGAWA, H.; OKAMOTO, Y.; MISAKI, T.; SUGIMURA, T. Preparation of $\mathrm{Pd} / \mathrm{C}$ designed for chiral modified catalyst: Comparison with $\mathrm{Pd} / \mathrm{TiO}_{2}$ in enantioselective hydrogenation of $\alpha$-phenylcinnamic acid. App. Catal. A: Gen., v. 437-438, p. 18-23, 2012

LONG, Y.; GUO, F.; FANG, Z.; TIAN, X.; JIANG, L.; ZHANG, F. Production of biodiesel and lactic acid from rapeseed oil using sodium silicate as catalyst. Biores. Tech., v. 102, p. 6884-6886, 2011

SEMIKOLENOV, V. A. Modern approaches to the preparation of "palladium on charcoal" catalysts. Rus. Chem. Rev., v. 61, p. 168-173, 1992

SHAMSIJAZEYI, H.; KAGHAZCHI, T. Investigation of nitric acid treatment of activated carbon for enhanced aqueous mercury removal. J. Ind. Eng. Chem., v. 16, p. 852-858, 2010

SHEN, Z.; JIN, F.; ZHANG, Y.; WU, B.; KISHITA, A.; TOHJI, K.; KISHIDA, H. Effect of alkaline catalysts on hydrothermal conversion of glycerin into lactic acid. Ind. Eng. Chem. Res., v. 48, p. 8920-8925, 2009

TOEBES, M. L.; DILLEN, J. A.; JONG, K. P. Synthesis of supported palladium catalysts. J. Mol. Catal. A: Chem., v. 173, p. 75-98, 2001

ZHOU, C.; BELTRAMINI, J. N.; FAN, Y.; LU, G. Q. Chemoselective catalytic conversion of glycerol as a biorenewable source to valuable commodity chemicals. Chem. Soc. Rev., v. 37, p. 527-549, 2008 